\title{
Safety of sublingual-swallow immunotherapy in children aged 3 to 7 years
}

Alessandro Fiocchi, MD*; Giovanbattista Pajno, MD †; Stefania La Grutta, MD Francesco Pezzuto, MD§; Cristoforo Incorvaia, MDI; Laura Sensi, MD\|; Francesco Marcucci, MD\|; and Franco Frati, MD\|

Background: The minimum age to start specific immunotherapy with inhalant allergens in children has not been clearly established, and position papers discourage its use in children younger than 5 years.

Objective: To assess the safety of high-dose sublingual-swallow immunotherapy (SLIT) in a group of children younger than 5 years.

Methods: Sixty-five children (51 boys and 14 girls; age range, 38-80 months; mean \pm SD age, $60 \pm 10$ years; median age, 60 months) were included in this observational study. They were treated with SLIT with a build-up phase of 11 days, culminating in a top dose of 300 IR (index of reactivity) and a maintenance phase of 300 IR 3 times a week. The allergens used were house dust mites in 42 patients, grass pollen in 11 patients, olive pollen in 5 patients, Parietaria pollen in 4 patients, and cypress pollen in 3 patients. All adverse reactions and changes in the treatment schedule were compared in 2 subgroups: children 38 to 60 months old and children 61 to 80 months old.

Results: The average cumulative dose of SLIT was 36,900 IR. Adverse reactions were observed in 11 children, none of them severe enough to require discontinuation of immunotherapy. Six reactions occurred in the 60 months or younger age group and 7 in the older than 60 months age group, with no differences between these 2 groups.

Conclusion: High-dose immunotherapy in children younger than 5 years does not cause more adverse reactions than in children aged 5 to 7 years. There is no reason to forbear studies on safety and efficacy of these preparations in young children.

Ann Allergy Asthma Immunol. 2005;95:254-258.

\section{INTRODUCTION}

Concerns over adverse reactions and compliance have led to the development of sublingual-swallow immunotherapy (SLIT) as distinct from, and in addition to, the subcutaneous administration of allergy vaccines. ${ }^{1-3}$ SLIT is gaining clinical acceptance, although no consensus exists regarding its efficacy. ${ }^{4}$ SLIT has been proposed as particularly appropriate and safe for children, ${ }^{5}$ but few safety data have targeted pediatric populations. ${ }^{6-10}$ Safety is often deduced from studies that include children but do not report their ratio to adult patients. ${ }^{11-15}$ Few studies include children younger than 5 years. $6,7,16$

The 1993 European Academy of Allergology and Clinical Immunology position paper advises avoidance of immunotherapy for children younger than 5 years. ${ }^{17}$ Thus, European health care professionals have been reluctant to prescribe

\footnotetext{
* Department of Child and Maternal Medicine, The Fatebenefratelli/Melloni University Hospital, Milan, Italy.

$\dagger$ Department of Pediatrics, University School of Medicine, Messina, Italy.

$\ddagger$ Allergy Unit, Children Hospital, ARNAS, Palermo, Italy.

$\S$ Allergy Unit, ASL SA2, Salerno, Italy.

II Allergy/Rheumatology Unit, ICP Hospital, Milan, Italy.

|| Department of Gynaecologic, Obstetric and Pediatric Sciences, University

School of Medicine, Perugia, Italy.

Received for publication November 30, 2004.

Accepted for publication in revised form March 4, 2005.
}

specific immunotherapy in very young children. ${ }^{18}$ However, the 1998 World Health Organization position paper merely lists age for initiation of immunotherapy among "research needs" and advises specialist evaluation..$^{19}$ The 2001 Allergic Rhinitis and Its Impact on Asthma (ARIA) Workgroup and World Health Organization document states that immunotherapy, including SLIT, should be initiated early in the disease process, but minimum age for onset of treatment is not specified. ${ }^{20}$ The 2003 Joint Task Force position paper of the American College of Asthma, Allergy and Immunology and the American Academy of Allergy, Asthma and Immunology mentions age at onset of immunotherapy as a clinical problem of "cooperation." ${ }^{21}$ Thus, the position that "there is no absolute cut-off ... with respect to the youngest age at which allergen immunotherapy should be considered" remains an open-ended research question..$^{22}$ In clinical practice, however, prescription of specific immunotherapy is gaining ground in pediatrics. In many regions of Italy, allergy vaccines are supplied free of charge and immunotherapy is administered in hospital for a minimal fee. Thus, the number of young children receiving immunotherapy is increasing in the absence of evidence-based restraints to prescriptions. In this context, we designed a pilot study to evaluate during a 1 -year period whether the 5 -year cutoff point is relevant in terms of safety for children aged 3 to 7 years already receiving SLIT for asthma and/or rhinoconjunctivitis. 


\section{PATIENTS AND METHODS}

\section{Design}

The study was designed as an observational, multicenter, minimization study of SLIT prescribed for the treatment of rhinoconjunctivitis and/or asthma in children younger than 7 years. Selection criteria balanced a number of diagnostic, clinical, and prognostic factors obtained from a questionnaire. ${ }^{23,24}$ Entry criteria were as follows: age between 36 and 84 months, monosensitization to pollen or mite allergen, intermittent-severe or persistent rhinoconjunctivitis according to ARIA criteria or level I or II allergic asthma according to the Global Initiative for Asthma (GINA) criteria or both rhinoconjunctivitis and asthma, and pharmacologic medication appropriate to each GINA and ARIA staging. Parents were instructed to use the following rescue medications: for rhinitis, nasal fluticasone, $50 \mu \mathrm{g}$ (Flixonase, GlaxoSmithKline, Uxbridge, England) as a nasal spray; for conjunctivitis, levocabastine, $0.5 \mathrm{mg} / \mathrm{mL}$ (Livostin, Jansen-Cilag, Birkerød, Denmark) as ocular drops; and for asthma symptoms, salbutamol (Ventolin, GlaxoSmithKline) as metered-dose inhaler. The research question was whether children younger than 5 years have an increase in adverse events with a high dose of SLIT. The primary outcome was the occurrence and the severity of adverse reaction irrespective of triggering dose or phase of treatment (either build-up or maintenance).

\section{Patients}

Children were recruited among outpatients who attended the pediatric departments of Milan, Messina, Palermo, Salerno, and Perugia, Italy, between January and December 2002, and observation was continued for at least 1 year until December 2003. Children younger than 84 months at the onset of SLIT were selected according to the minimization criteria listed herein. Diagnosis and staging were performed by a pediatric allergist with the exclusion of relevant nonallergic triggers of rhinitis and asthma. After selection, parents of patients gave written informed consent. The study was approved by the ethical committees of participating centers.

\section{SLIT Schedules}

Children were treated with Staloral 300 (Stallergènes, Antony, France). The allergen extract was graded into concentrations of $1,10,100$, and 300 IR (index of reactivity) per milliliter. The IR is a unit of allergenic activity specific to the Stallergènes laboratory: a 100-IR extract is defined by its capacity to induce a mean wheal diameter of $7 \mathrm{~mm}$ in skin prick tests in a panel of 30 patients sensitized to the allergen considered. The build-up phase was performed as suggested by the manufacturer in 11 days with a top dose of $300 \mathrm{IR}$, and the maintenance phase dose was 300 IR 3 times a week. Drops were deposited under the tongue and held for 1 minute before being swallowed.

\section{Safety}

Adverse reactions and changes in treatment schedule were recorded by means of an ad hoc questionnaire. Reaction severity was classified according to a 0 - to 5-point scale (Table 1). ${ }^{25}$ For the purpose of analysis, clinicians were allowed to rank the different reaction types as reported in Table 2. Phase of treatment (build-up or maintenance), dose that elicited the adverse reaction, and the interval between dose and reaction were recorded.

\section{Statistical Analysis}

Hypotheses were tested by the Fisher exact test, the null hypothesis being that the median adverse event scores of the children who participated in the intervention would not change because of SLIT before or after 60 months. Data were expressed as nominal categories on a binomial scale, and the distribution of adverse effects by age was analyzed by the binomial test.

\section{RESULTS}

Sixty-five children (14 girls and 51 boys; age range, 38-80 months; mean \pm SD age, $60 \pm 10$ months; median age, 60 months) were observed. They were divided into 2 subgroups: 38 to 60 months ( 6 girls and 27 boys; mean \pm SD age at onset, $52 \pm 6.0$ months) and 61 to 80 months (8 girls and 24 boys; mean \pm SD age at onset, $70 \pm 10.6$ months). The mean duration of treatment was $246 \pm 161$ days. The average cumulative dose of SLIT in the study population was $36,900 \pm 1,872$ IR $(36,200 \pm 1,227$ for the group 5 years or younger and $37,600 \pm 2,142$ in the older group). Extracts used were house dust mites in 42 patients, grass in 11 patients, olive tree in 5 patients, Parietaria in 4 patients, and cypress pollens in 3 patients.

In the present series, SLIT, administered with a cumulative dose more than 300 times higher than the standard dose recommended with subcutaneous immunotherapy, was tolerated without adverse events in 54 of 65 cases, whereas 11 patients experienced 13 adverse reactions. Table 3 lists reactions according to patient age in the 2 groups: 6 reactions were recorded in 5 patients in the group of patients who started treatment 60 months or younger and 7 reactions were recorded in 6 patients in the group older than 60 months. Six

Table 1. Assessment of the Severity of Adverse Reactions by a 5Point Scale

\begin{tabular}{lc}
\hline \multicolumn{1}{c}{ Reaction } & Score \\
\hline No reaction & 0 \\
Mild reaction (not requiring medical attention) & 1 \\
$\begin{array}{l}\text { Mild-to-moderate reaction (requires medical care but } \\
\text { neither drug treatment nor modification of SLIT }\end{array}$ & 2 \\
$\quad$ schedule) & 3 \\
$\begin{array}{l}\text { Moderate reaction (requires either SLIT schedule } \\
\text { modification or drug treatment) }\end{array}$ & 4 \\
$\begin{array}{l}\text { Moderate-to-severe reaction (requires both drug } \\
\text { treatment and temporary interruption of SLIT } \\
\text { schedule) }\end{array}$ & \\
$\begin{array}{l}\text { Severe reaction (requires emergency department visit or } \\
\text { hospitalization) }\end{array}$ & 5 \\
\hline
\end{tabular}

Abbreviation: SLIT, sublingual-swallow immunotherapy. 
Table 2. Questionnaire for the Evaluation of Adverse Reactions and Severity Rank for Each Item

\begin{tabular}{lc}
\hline Adverse reaction & Severity rank \\
\hline None & 0 \\
Local adverse reaction & \\
Orolabial itching & $0-2$ \\
Labial edema & $0-3$ \\
Nausea and vomiting & $0-4$ \\
Colic, diarrhea & $0-4$ \\
Respiratory adverse reaction & \\
Rhinitis & $0-4$ \\
Cough & $0-4$ \\
Asthma & $0-5$ \\
Cutaneous adverse reaction & \\
Eczema & $0-4$ \\
Urticaria & $0-5$ \\
Angioedema & $0-5$ \\
Other (specify) & $0-5$ \\
\hline
\end{tabular}

reactions occurred in the build-up phase and 7 in the maintenance phase, all ranging from mild to moderate and not requiring SLIT cessation. Adjustments were necessary in 9 cases with the conventional schedule and in 2 (moderate reaction) with a reduced maintenance dose. Reactions in the maintenance phase occurred 40 to 350 days from onset of SLIT. Dust mite allergen, used in $64.6 \%$ of programs, was responsible for $76.9 \%$ of adverse reactions. The occurrence of adverse reactions was independent of age $\left(\chi^{2}=0.0348\right)$. The magnitude of adverse effects is illustrated by the joint probability by age of 5 years or younger according to the multiplication rule. Among children 60 months or younger, these probabilities were 0.08 and 0.11 in older children. Analysis of the binomial distribution reveals that the probability of an adverse outcome for a single patient is similar 60 months or younger $(0.16 ; \mathrm{SD}, 2.34)$ and older than 60 months $(0.17$; SD, 2.20).

\section{DISCUSSION}

This is the first study, to our knowledge, to evaluate whether a 5-year age limitation is clinically justified on safety grounds among children receiving SLIT for asthma and allergic rhinitis. In the literature, no absolute prohibition has been linked to a rationale based on a risk increase in patients younger than this age. Caution is recommended in the evaluation of the tradeoffs of immunotherapy for individual patients. However, this 5-year watershed may be a deterrent to the prescription of SLIT at the very age when the allergic march starts and when the early diagnosis of atopy should be made. ${ }^{26,27}$ Furthermore, a preventive effect of specific immunotherapy on the natural history of allergic disease may be lost with later onset of therapy. ${ }^{28,29}$

We did not set out to evaluate the safety of SLIT in young children, but evaluated young Italian children who received SLIT as part of the management of their asthma or rhinoconjunctivitis irrespective of the reason why SLIT had been prescribed. This particular formulation has been proven effective in children. ${ }^{23}$ Thus, adverse events in response to individual allergens were not evaluated. The main result of this study was that on either side of the 5-year cutoff there was no significant difference in occurrence of adverse reactions. This finding suggests that younger age does not rule out contemplating the prescription of SLIT when clinically indicated. The few adverse reactions that occurred were low in severity. No major clinical differences occurred among these unselected children across the 60-month age limit during a 1 -year period of observation. In this series, the unweighted frequency of adverse reactions was $16.9 \%$, which agrees with the findings from selected populations studied under placebo-

Table 3. Adverse Reactions and Severity in 11 Children

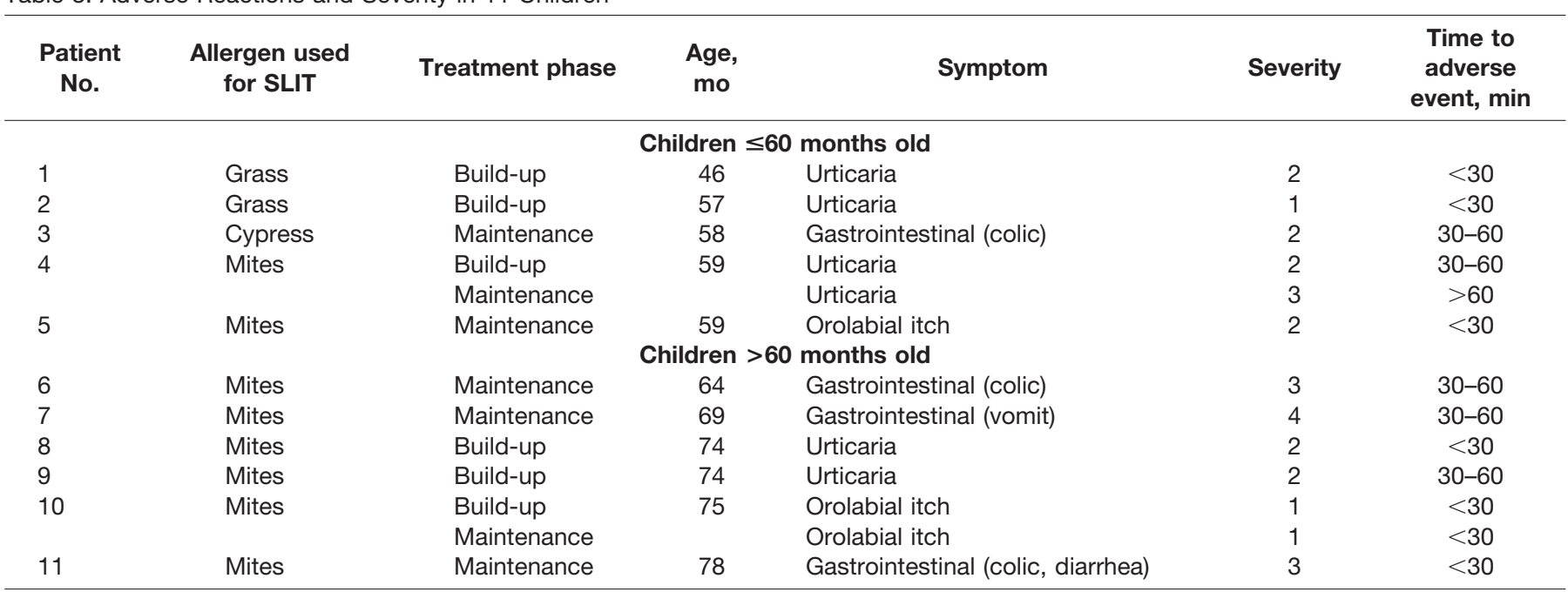

Abbreviation: SLIT, sublingual-swallow immunotherapy. 
controlled conditions among whom the rate of adverse reactions to SLIT was $6.25 \%{ }^{13}$ to $49 \% .^{14}$

Treatment with SLIT with house dust mites, the build-up phase, and errors in dosage and compliance are among the risk factors for systemic reactions associated with subcutaneous immunotherapy. The waiting period following injection has been set at 30 minutes, because most untoward reactions tend to be immediate. ${ }^{17,30}$ In our series, most adverse effects occurred after SLIT with house dust mites, and 53.8\% of reactions occurred during the build-up phase, underscoring the critical clinical point represented by this stage of SLIT. All but 1 reaction occurred within 60 minutes of administration, suggesting another critical clinical phase. All these findings are reminiscent of data from the literature on subcutaneous immunotherapy.

The limits of the present study are those of an observational study of adverse effects, because we could not, by design, evaluate the clinical effects of SLIT in an unselected population of children. Our aim was to examine the situation during a 1-year period in the sociomedical Italian context, where allergy vaccines are more readily available for prescription.

Our data suggest that there is no reason to forbear assessing safety and efficacy of SLIT beyond this pilot study on account of age of 5 years or younger. Because the efficacy of specific immunotherapy is said to be higher among younger children, ${ }^{18}$ further well-controlled clinical studies are needed to establish the safety of SLIT among toddlers. These studies should also address the clinical relevance of single allergens as risk factors.

\section{ACKNOWLEDGMENT}

The authors acknowledge the contribution of Gabriel R. Bouygue to the statistical model and to the manuscript.

\section{REFERENCES}

1. Businco L, Zannino L, Cantani A, Corrias A, Fiocchi A, La Rosa M. Systemic reactions to specific immunotherapy in children with respiratory allergy: a prospective study. Pediatr Allergy Immunol. 1995;6:44-47.

2. Cantani A, Arcese G, Lucenti P, Gagliesi D, Bartolucci M. A three-year prospective study of specific immunotherapy to inhalant allergens: evidence of safety and efficacy in 300 children with allergic asthma. J Investig Allergol Clin Immunol. 1997;7:90-97.

3. Akcakaya N, Hassanzadeh A, Camcioglu Y, Cokugras H. Local and systemic reactions during immunotherapy with adsorbed extracts of house dust mite in children. Ann Allergy Asthma Immunol. 2000;85:317-321.

4. Wilson DR, Torres LM, Durham SR. Sublingual immunotherapy for allergic rhinitis. Cochrane Database Syst Rev. 2003;(2): CD002893.

5. Passalacqua G, Guerra L, Pasquali M, Lombardi C, Canonica GW. Efficacy and safety of sublingual immunotherapy. Ann Allergy Asthma Immunol. 2004;93:3-12.

6. Di Rienzo V, Pagani A, Parmiani S, Passalacqua G, Canonica GW. Post-marketing surveillance study on the safety of sublingual immunotherapy in children. Allergy. 1999;54:1110-1113.
7. Di Rienzo V, Marcucci F, Puccinelli P, et al. Long lasting effect of sublingual immunotherapy in children with asthma due to house dust mites: a 10-year prospective study. Clin Exp Allergy. 2003;33:206-210.

8. Pajno GB, Morabito L, Barberio G, Parmiani S. Clinical and immunologic effects of long-term sublingual immunotherapy in asthmatic children sensitized to mites: a double-blind, placebocontrolled study. Allergy. 2000;55:842-849.

9. Ippoliti F, De Santis W, Volterrani A, et al. Immunomodulation during sublingual therapy in allergic children. Pediatr Allergy Immunol. 2003; 14:216-221.

10. Marcucci F, Sensi L, Frati F, et al. Sublingual tryptase and ECP in children treated with grass pollen sublingual immunotherapy (SLIT): safety and immunologic implications. Allergy. 2001;55: 1091-1095.

11. Guez S, Vatrinet C, Fadel R, Andre C. House-dust-mite sublingual-swallow immunotherapy (SLIT) in perennial rhinitis: a double-blind, placebo-controlled study. Allergy. 2000;55: 369-375.

12. Mortemousque B, Bertel F, De Casamayor J, Verin P, Colin J. House-dust mite sublingual-swallow immunotherapy in perennial conjunctivitis: a double-blind, placebo-controlled study. Clin Exp Allergy. 2003;33:464-469.

13. Tonnel AB, Scherpereel A, Douay B, et al. Allergic rhinitis due to house dust mites: evaluation of the efficacy of specific sublingual immunotherapy. Allergy. 2004;59:491-497.

14. Moreno C, Cuesta-Herranz J, Fernandez-Tavora L, et al. Immunotherapy safety: a prospective multi-centric monitoring study of biologically standardized therapeutic vaccines for allergic diseases. Clin Exp Allergy. 2004;34:527-531.

15. Bowen T, Greenbaum J, Charbonneau Y, et al. Canadian trial of sublingual swallow immunotherapy for ragweed rhinoconjunctivitis. Ann Allergy Asthma Immunol. 2004;93:425-430.

16. Rolinck-Werninghaus $\mathrm{C}$, Wolf $\mathrm{H}$, Liebke $\mathrm{C}$, et al. A prospective, randomized, double-blind, placebo-controlled multi-centre study on the efficacy and safety of sublingual immunotherapy (SLIT) in children with seasonal allergic rhinoconjunctivitis to grass pollen. Allergy. 2004;59:1285-1293.

17. Malling HJ, Weeke B. Immunotherapy: position paper. Allergy. 1993;48(14 suppl):9-35.

18. Ownby DR, Adinoff AD. The appropriate use of skin testing and allergen immunotherapy in young children. J Allergy Clin Immunol. 1994;94:662-665.

19. Bousquet J, Lockey R, Malling HJ. Allergen immunotherapy: therapeutic vaccines for allergic diseases [WHO Position Paper]. J Allergy Clin Immunol. 1998;102(4 pt 1):558-562.

20. Bousquet J, Van Cauwenberge P, Khaltaev N, ARIA Workshop Group, World Health Organization. Allergic rhinitis and its impact on asthma. J Allergy Clin Immunol. 2001;108(5 suppl): S147-S334.

21. Li JT, Lockey RF, Bernstein IL, Portnoy JM, Nicklas RA, Eds. Allergen immunotherapy: a practice parameter. Ann Allergy Asthma Immunol. 2003;90:1-40.

22. DuBuske LM. Appropriate and inappropriate use of immunotherapy. Ann Allergy Asthma Immunol. 2001;87(suppl 1): $56-67$.

23. Taves DR. Minimization: a new method of assigning patients to treatment and control groups. Clin Pharmacol Ther. 1974;15: 443-453.

24. Moher D, Schulz KF, Altman D, for the CONSORT group. The CONSORT statement: revised recommendations for improving 
the quality of reports or parallel-group randomized trials. Ann Intern Med. 2001;134:657-694.

25. Frati F, Sensi L, Di Rienzo V, Senna GE, Incorvaia C, Marcucci F. A model for management of sublingual immunotherapy. Allerg Immunol (Paris). 2003;35:56-60.

26. Host A, Andrae S, Charkin S, Diaz-Vazquez C, et al. Allergy testing in children: why, who, when and how? Allergy. 2003; 58:559-569.

27. Fiocchi A, Besana R, Ryden AC, et al. Differential diagnosis of IgE-mediated allergy in young children with wheezing or eczema symptoms using a single blood test. Ann Allergy Asthma Immunol. 2004;93:328-333.

28. Agertoft L, Pedersen S. Effects of long-term treatment with an inhaled corticosteroid on growth and pulmonary function in asthmatic children. Respir Med. 1994;88:373-381.
29. Moller C, Dreborg S, Ferdousi HA, et al. Pollen immunotherapy reduces the development of asthma in children with seasonal rhinoconjunctivitis (the PAT-study). J Allergy Clin Immunol. 2002;109:251-256.

30. Reid MJ, Lockey RF, Turkeltaub PC, Platts-Mills TAE. Survey of fatalities from skin test and immunotherapy 1985-1989. $J$ Allergy Clin Immunol. 1993;92:6-15.

Requests for reprints should be addressed to:

Alessandro Fiocchi, MD

Macedonio Melloni Pediatric Hospital

Via Macedonio Melloni 52

20121 Milan, Italy

E-mail: allerg@tin.it

Answers to CME examination-Annals of Allergy, Asthma \& Immunology, September 2005 Lieberman P: Biphasic anaphylactic reactions. Ann Allergy Asthma Immunol. 2005;95:217-226.

1. e

2. a

3. a

4. e

5. e 